\title{
ANALISIS KETAHANAN PANGAN RUMAH TANGGA DI DESA KALIREJO KECAMATAN KOKAP KABUPATEN KULON PROGO
}

\author{
Analysis of Food Security in Desa Kalirejo Kecamatan Kokap Kabupaten Kulon \\ Progo
}

\author{
Ekinanda Anggita Sadevi, Siti Hamidah, Ni Made Suyastiri Yani Permai \\ Program Studi Agribisnis Jurusan Agribisnis, Fakultas Pertanian, Universitas \\ Pembangunan Nasional Veteran Yogyakarta \\ Jl. SWK 104 (Lingkar Utara) Condong Catur Yogyakarta Indonesia 55283 \\ *email korespondensi : ekinandaa@gmail.com
}

Diterima tanggal : 5 Oktober 2020 ; Disetujui tanggal : 15 Oktober 2020

\begin{abstract}
This research aimed to analyze: (1) the food security level of the household, and (2) the factors that influenced to food consumption level. The basic method that used in this research was descriptive-analytical. Research implementation method used survey, and research location determination used a purposive sampling method in Kalirejo village with 43 household as respondents that selected with systematic random sampling. Data used in this research were primary data and secondary data. The technique of data collection used interview, observation, and report. Data analysis used One Sample t-test and Multiple Linear Regression. Food security level analyze using cross-classification between food expenditure share and energy adequacy level. The results of this research showed that: (1) The average of household food security level in Kalirejo village is in the susceptible food category. (2) length of education for housewives, number of household members, and income influenced food consumption in Kalirejo village.
\end{abstract}

Keywords: consumption of energy, food expenditure share, food security.

\begin{abstract}
ABSTRAK
Penelitian ini bertujuan untuk (1) Menganalisis tingkat ketahanan pangan rumah tangga, dan (2) Menganalisis faktor-faktor yang mempengaruhi konsumsi pangan tingkat rumah tangga. Metode dasar yang digunakan pada penelitian ini adalah metode deskriptif analitis. Metode pelaksanaan penelitian menggunakan metode survei, dan penentuan lokasi penelitian menggunakan metode purposive sampling. Lokasi penelitian dipilih secara sengaja di Desa Kalirejo, Kokap, Kulon Progo dengan responden sebanyak 43 rumah tangga yang dipilih dengan metode systematic sampling. Jenis data yang digunakan dalam penelitian ini adalah data primer dan sekunder. Teknik pengumpulan data dengan wawancara, observasi, dan pencatatan. Teknik analisis untuk menguji hipotesis pada konsumsi energi dan pangsa pengeluaran pangan menggunakan One Sample T-test. Teknik analisis untuk mengetahui tingkat ketahanan pangan menggunakan klasifikasi silang
\end{abstract}


antara pangsa pengeluaran pangan dan tingkat kecukupan energi. Teknik analisis untuk menguji hipotesis faktor yang mempengaruhi konsumsi energi menggunakan analisis Regresi Linear Berganda. Hasil penelitian menunjukkan (1) Rata- rata tingkat ketahanan pangan rumah tangga di Desa Kalirejo berada dalam kategori rentan pangan. (2) lama pendidikan ibu rumah tangga, jumlah anggota rumah tangga dan pendapatan berpengaruh terhadap konsumsi pangan di Desa Kalirejo, Kokap, Kulon Progo.

\section{Kata kunci : ketahanan pangan, konsumsi energi, pangsa pengeluaran pangan}

\section{PENDAHULUAN}

Pangan dalam hirarki kebutuhan manusia adalah salah satu kebutuhan yang paling dasar sehingga pemenuhan pangan merupakan bagian dari hak asasi setiap orang. Bahkan ketahanan pangan merupakan pilar utama dalam pembangunan nasional dan identik dengan ketahanan nasional (Dirhamsyah et al, 2016). Undang-Undang Republik Indonesia Nomor 18 Tahun 2012 tentang Pangan, mengartikan ketahanan pangan sebagai kondisi terpenuhinya pangan bagi negara sampai dengan perseorangan yang tercermin dari tersedianya pangan yang cukup, baik jumlah maupun mutunya, aman, beragam, bergizi, merata dan terjangkau serta tidak bertentangan dengan agama, keyakinan, dan budaya masyarakat, untuk dapat hidup aktif, sehat dan produktif secara berkelanjutan.

Menurut Suryana (2014) ketahanan pangan merupakan suatu sistem yang terdiri atas subsistem ketersediaan, keterjangkauan serta pemanfaatan. Ketersediaan dan keterjangkauan memfasilitasi pasokan pangan yang stabil serta merata dari seluruh wilayah dan juga memantapkan kerawanan pangan untuk mengurangi jumlah penduduk miskin maupun kelaparan. Sedangkan subsistem pemanfaatan atau konsumsi memungkinkan setiap rumah tangga memperoleh pangan yang cukup dan memanfaatkannya secara bertanggungjawab untuk memenuhi kebutuhan gizi seluruh anggotanya.

Konsumsi pangan dilakukan untuk memperoleh zat gizi yang bermanfaat bagi tubuh. Konsumsi pangan menunjukkan gambaran jumlah bahan makanan yang rata-rata dikonsumsi oleh anggota masyarakat (Sitompul, 2016). Konsumsi pangan sangat penting dalam rumah tangga, karena konsumsi pangan tersebut dapat menggambarkan sisi ekonomi rumah tangga, yaitu bagaimana rumag tangga 
memproporsikan pendapatan yang dimilikinya. Sehingga konsumsi pangan dapat dijadikan indikator untuk melihat tingkat kesejahteraan ekonomi masyarakat (Mayasari, 2018). Menurut Ambarsari (2017), terdapat 3 faktor yang mempengaruhi konsumsi pangan yaitu pendidikan ibu rumah tangga, pendapatan rumah tangga dan jumlah anggota rumah tangga. Pendapatan ibu rumah tangga berpengaruh terhadap pengetahuan ibu rumah tangga mengenai jenis dan gizi pangan yang dikonsumsi. Semakin lama pendidikan ibu rumah tangga maka pengetahuan akan gizi pangan akan lebih baik, sehingga pangan yang dikonsumsi lebih bergizi. Jumlah anggota rumah tangga berpengaruh terhadap banyaknya pangan yang dikonsumsi. Semakin banyak jumlah anggota rumah tangga maka pangan yang dikonsumsi akan semakin beragam karena setiap anggota rumah tangga memiliki selera yang berbeda. Dalam Hukum Engel dalam Nicholson (1994) menyebutkan bahwa rumah tangga yang memiliki pendapatan rendah mengeluarkan sebagian besar pendapatannya untuk membeli kebutuhan pokok yaitu pangan.

Kabupaten Kulon Progo merupakan suatu daerah dengan luas wilayah sebesar 58.627,51 Ha dengan populasi tahun 2018 sebanyak 421,295 jiwa yang tersebar di 12 kecamatan. Kabupaten Kulon Progo salah satu kabupaten bagian dari Daerah Istimewa Yogyakarta yang terletak di bagian barat Kota Yogyakarta dan berbatasan langsung dengan Kabupaten Bantul dan Kabupaten Sleman. Sektor pertanian menjadi tumpuan ekonomi di Kabupaten Kolon Progo. Pada tahun 2018, Kabupaten Kulon Progo mampu memproduksi padi sawah sebanyak 10.254 Ha (BPS, 2018). Meskipun hasil produksi pertaniannya cukup melimpah, namun masih terdapat permasalahan terkait pangan di Kabupaten Kulon Progo yaitu masih terdapat Desa Rawan Pangan.

Desa Kalirejo, Kecamatan Kokap, Kabupaten Kulon Progo merupakan desa rawan pangan dengan jumlah penduduk belum sejahtera paling banyak di Kabupaten Kulon Progo. Dalam penilaian desa rawan pangan terdapat 3 aspek yang dinilai yaitu aspek ketersediaan pangan, aspek pemanfaatan pangan dan aspek akses pangan (Dinas Pertanian dan Ketahanan Pangan, 2018). Desa Kalirejo menjadi desa rawan pangan dengan nilai pada aspek pemanfaatan paling rendah. 
Hal tersebut berkaitan dengan jumlah penduduk belum sejahtera paling tinggi, karena pada rumah tangga yang belum sejahtera tersebut cenderung kesulitan untuk mengakses pangan yang dikonsumsi. Rumah tangga yang belum sejahtera kesulitan dalam daya beli untuk pangannya, daya beli sendiri ditentukan oleh besaran pendapatan dan harga komoditas pangan. Hasilnya pemenuhan pangan rumah tangga belum sejahtera cenderung akan memilih pangan yang murah dan mudah ditemukan tanpa memperhatikan gizi pangan tersebut. Tidak heran hasil penilaian analisis pangan dan gizi di Desa Kalirejo menunjukkan nilai rendah pada aspek pemanfaatan pangan.

Sebagian besar penduduk di Desa Kalirejo, Kecamatan Kokap, Kabupaten Kulon Progo merupakan pengrajin gula semut. Harga gula yang berkisar Rp 15.000 sampai dengan Rp 17.000 per kilo dan pembuatan gula semut tingkat rumah tangga hanya mampu menghasilkan gula semut sejumlah 2-4 $\mathrm{kg}$ per harinya tentu saja membuat terbatasnya pangan yang akan dikonsumsinya. Minimnya upah tersebut dapat berdampak terhadap akses untuk mendapatkan jenis bahan pangan yang dikonsumsi masyarakat. Keterbatasan pendapatan menyebabkan pemilihan bahan pangan yang dikonsumsi lebih terbatas padahal masyarakat harus memenuhi kebutuhan pangan setiap anggota kelurganya juga.

\section{METODE PENELITIAN}

Metode dasar penelitian menggunakan metode Deskriptif Analitis, yaitu suatu metode penelitian yang dilakukan untuk menganalisis data secara statistik dengan cara mendeskripsikan atau menggambarkan data yang telah terkumpul sebagaimana adanya tanpa bermaksud membuat kesimpulan yang berlaku untuk umum atau generalisasi (Sugiyono, 2017). Metode pelaksanaan penelitian menggunakan metode survei, sehingga dapat membedah dan mengenal masalah serta dapat mendapatkan pembenaran terhadap keadaan yang berlangsung. Metode survei tersebut dapat digunakan untuk membuat rencana dan pengambilan keputusan di masa mendatang.

Metode penentuan lokasi menggunakan purposive sampling yang merupakan cara pengambilan sampel dengan pertimbangan tertentu (Sugiyono, 
2017). Pertimbangan bahwa suatu daerah tergolong ke dalam desa rawan pangan dengan jumlah rumah tangga belum sejahtera paling tinggi, dan didapatkan bahwa Desa Kalirejo, Kecamatan Kokap, Kabupaten Kulon Progo memenuhi kriteria tersebut.

Metode pengambilan responden menggunakan Systematic Random Sampling adalah suatu cara untuk pengambilan sampel dengan memberikan nomor pada setiap unit populasi dan diurutkan. Kemudian diambil satu sampel yang akan dijadikan sebagai titik tolak menarik sampel. Nomor berikut dari anggota yang ingin dipilih ditentukan secara sistematis, misalnya tiap nomor ke $\mathrm{m}$ dari titik tolak dan dari unit selanjutnya akan dipilih anggota sampel (Nazir, 1988). Populasi dalam penelitian sejumlah 1250 rumah tangga, dengan mengacu pada Rumus Slovin dalam Nazir (1988) maka sampel yang diambil sejumlah 43 rumah tangga.

Data yang dikumpulkan adalah data primer dan data sekunder. Data primer diperoleh melalui wawancara, observasi, pencatatan dan dokumentasi, serta Food Recall. Selain itu pengumpulan data primer menggunakan bantuan kuisioner. pengumpulan data sekunder diperoleh dari instansi terkait dan literatur yang berhubungan dengan penelitian. Pengambilan data dilakukan bulan Februari Maret 2020.

Pengujian data menggunakan 3 cara yaitu one sample t-test untuk menguji pangsa pengeluaran pangan dan tingkat kecukupan energi, Regresi Linear Berganda dan klasifikasi silang ketahanan pangan menurut Johnsson dan Toole dalam Dirhamsyah et al (2016) yang tersaji di tabel 1. Besaran pangsa pengeluaran pangan didapatkan dari perbandingan antara pengeluaran pangan dengan pengeluaran total. Tingkat kecukupan energi diperoleh dengan membandingkan konsumsi energi aktual dengan kecukupan energi yang dianjurkan Widyakarya Nasional Pangan dan Gizi (WNPG) 2018 yaitu sebesar $2.100 \mathrm{kkal} / \mathrm{kapita} / \mathrm{hari}$. 
Jurnal Dinamika Sosisal Ekonomi, 21 (2) : 205-218

Tabel 1.Pengukuran Ketahanan Pangan

\begin{tabular}{|c|c|c|}
\hline \multirow[b]{2}{*}{$\begin{array}{c}\text { Indikator Klasifikasi Silang } \\
\text { Pengukuran Derajat Ketahanan } \\
\text { Pangan }\end{array}$} & \multicolumn{2}{|c|}{ Pangsa Pengeluaran Pangan } \\
\hline & $\begin{array}{c}\text { Rendah } \\
(<60 \% \text { pengeluaran } \\
\text { total })\end{array}$ & $\begin{array}{c}\text { Tinggi } \\
\text { ( } \geq 60 \% \text { pengeluaran } \\
\text { total) }\end{array}$ \\
\hline $\begin{array}{c}\text { Konsumsi Energi per Unit } \\
\text { Ekuivalen Dewasa } \\
\text { Cukup } \\
(>80 \% \text { kecukupan energi) } \\
\end{array}$ & Tahan Pangan & Rentan Pangan \\
\hline $\begin{array}{c}\text { Kurang } \\
(\leq 80 \% \text { kecukupan energi) }\end{array}$ & Kurang Pangan & Rawan Pangan \\
\hline
\end{tabular}

Sumber : Jonsson dan Toole (1991) dalam Dirhamsyah et al (2016)

Pengukuran faktor-faktor yang mempengaruhi konsumsi pangan rumah tangga digunakan model regresi linear berganda sebagai berikut:

$$
y=a+b_{1} x_{1}+b_{2} x_{2}+b_{3} x_{3}+e
$$

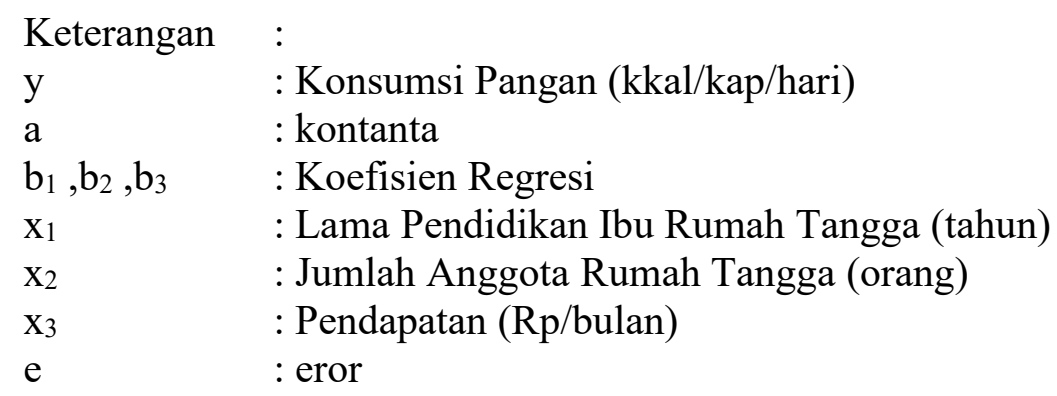

\section{HASIL DAN PEMBAHASAN}

\section{Pangsa Pengeluaran Pangan}

Pangsa pengeluaran pangan merupakan perbandingan pengeluaran rumah tangga untuk pengeluaran pangan dibandingkan dengan pengeluaran total rumah tangga. Pengeluaran rumah tangga dapat digolongkan menjadi dua, yaitu pengeluaran pangan dan pengeluaran non pangan. Pangsa Pengeluaran pangan merupakan besarnya jumlah total pengeluaran rumah tangga untuk belanja pangan dari jumlah total pengeluaran rumah tangga (Delly, 2018). Tabel 2 menunjukkan bahwa pengeluaran pangan rumah tangga paling tinggi adalah pada pengeluaran padi-padian, bahan makanan lain dan kacang-kacangan, yaitu masing-masing sebesar $31,26 \%, 25,09 \%$ dan $12,11 \%$ dari total pengeluaran pangan. 
Sadevi Et.Al. Analisis Ketahanan Pangan Rumah Tangga Di Desa Kalirejo

Tabel 2. Rata-Rata Pengeluaran Pangan per Bulan Rumah Tangga di Desa Kalirejo

\begin{tabular}{lcc}
\hline \multicolumn{1}{c}{ Pengeluaran Pangan } & Rata-Rata (Rp/Bulan) & Persentase (\%) \\
\hline Padi-Padian & $268.779,07$ & 31,26 \\
Umbi-umbian & $17.081,40$ & 1,99 \\
Pangan Hewani & $51.976,74$ & 6,04 \\
Telur dan Susu & $61.988,37$ & 7,21 \\
Sayur-sayuran & $73.313,95$ & 8,53 \\
Kacang-kacangan & $104.123,26$ & 12,11 \\
Buah-buahan & $21.267,44$ & 2,47 \\
Minyak dan Kelapa & $45.590,70$ & 5,30 \\
Bahan Makanan Lain & $215.710,84$ & 25,09 \\
\hline & $859.831,77$ & 100,00 \\
\hline
\end{tabular}

Sumber : Analisis Data Primer, 2020

Selain pengeluaran pangan dihitung pula pengeluaran non pangan yang terdiri atas beberapa biaya lain. Hasilnya pada tabel 3 menunjukkan rata-rata pengeluaran non pangan paling tinggi terdapat pada biaya sekolah, biaya bahan bakar dan biaya listrik. Masing-masing sebesar 27,98\%, 17,32\% dan 12,17\%.

Tabel 3. Rata-rata Pengeluaran Non Pangan Rumah Tangga di Desa Kalirejo

\begin{tabular}{|c|c|c|}
\hline Pengeluaran Non Pangan & Rata-rata (Rp/bulan) & Persentase (\%) \\
\hline Biaya Air & $9.232,56$ & 1,67 \\
\hline LPG & $33.302,33$ & 6,02 \\
\hline Listrik & $67.290,70$ & 12,17 \\
\hline Pulsa & $35.488,37$ & 6,42 \\
\hline Perlengkapan Mandi & $35.986,05$ & 6,51 \\
\hline Sabun Cuci & $27.976,74$ & 5,06 \\
\hline Bahan Bakar & $95.767,44$ & 17,32 \\
\hline Biaya Sekolah & $154.744,19$ & 27,98 \\
\hline Sandang & $13.372,09$ & 2,42 \\
\hline Barang Elektronik & $6.618,60$ & 1,20 \\
\hline Pajak Bumi dan Bangunan & $7.329,30$ & 1,33 \\
\hline Pajak Kendaraan & $21.599,23$ & 3,91 \\
\hline Asuransi & $11.325,58$ & 2,05 \\
\hline Kredit & $33.023,26$ & 5,97 \\
\hline Keperluan Pesta & 0 & 0,00 \\
\hline Jumlah & $553.056,44$ & 100 \\
\hline
\end{tabular}

Sumber : Analisis Data Primer, 2020 
Jurnal Dinamika Sosisal Ekonomi, 21 (2) : 205-218

Pangsa pengeluaran pangan dihitung dari perbandingan pengeluaran pangan terhadap pengeluaran total. Hipotesis peneleitian pada pangsa pengeluaran pangan adalah diduga pangsa pengeluaran pangan memiliki kategori tinggi. Berikut merupakan hasil perhitungan pangsa pengeluaran pangan rumah tangga.

Tabel 4. Pangsa Pengeluaran di Desa Kalirejo

\begin{tabular}{lcc}
\hline \multicolumn{1}{c}{ Pengeluaran } & $\begin{array}{c}\text { Jumlah Pengeluaran } \\
\text { (Rp/Bulan) }\end{array}$ & $\begin{array}{c}\text { Persentase } \\
\text { (\%) }\end{array}$ \\
\hline Pengeluaran Pangan & $859.831,77$ & 60,86 \\
Pengeluaran Non Pangan & $553.056,44$ & 39,14 \\
\hline Pengeluaran Total & $1.412 .888,21$ & 100 \\
\hline
\end{tabular}

Sumber : Analisis Data Primer, 2020

Hasilnya pada tabel 4 menunjukkan bahwa pangsa pengeluaran pangan sebesar 60,86\% yang berarti lebih dari 60\% dan tergolong tinggi. Hasil pangsa pengeluaran pangan tersebut juga didukung dengan hasil uji one sample t-test sebagai berikut:

Tabel 5. Hasil Analisis One Sample t-test Pangsa Pengeluaran Pangan Rumah Tangga di Desa Kalirejo

\begin{tabular}{lcccc}
\hline \multicolumn{1}{c}{ Variabel } & N & Mean & t-hitung & P-value \\
\hline Pangsa Pengeluaran Pangan & 43 & 67,4781 & 3,193 &, 003 \\
\hline Test Value : 60 & & & &
\end{tabular}

Sumber : Analisis Data Primer, 2020

Tabel 5 menunjukkan bahwa pangsa pengeluaran pangan rumah tangga tergolong tinggi dengan rata-rata sebesar 67,4781 \%. Rumah tangga di Desa Kalirejo cenderung menggunakan pendapatannya untuk pemenuhan pangan terlebih dahulu. Hal tersebut sejalan dengan Hukum Engel tahun 1853 dalam Nicholson (1994) yang menyatakan bahwa proporsi pengeluaran pangan di negara berkembang cenderung lebih besar dibandingkan pengeluran non pangannya. Pangsa pengeluaran pangan akan terus tinggi selama rumah tangga masih berada dibawah garis kemiskinan yaitu nilai Upah Minimum Regional (UMR) Kabupaten Kulon Progo tahun 2020 yaitu sebesar Rp 1.750.500. perlu dilakukan suatu upaya oleh pemerintah bersama masyarakat untuk meningkatkan pendapatan. 


\section{Tingkat Kecukupan Energi}

Konsumsi pangan dapat dihitung secara kuantitatif dapat dihitung melalui konsumsi energi. Kualitas pangan menunjukkan adanya gizi yang dibutuhkan oleh tubuh, sedangkan kuantitatif menunjukkan jumlah gizi dalam suatu bahan pangan (Arida, 2015). Konsumsi energi dihitung dengan cara menentukan menentukan makanan atau minuman yang dikonsumsi oleh suatu rumah tangga yang kemudian dianalisis bahan pangan dalam masakan tersebut. Perhitungan konsumsi energi digunakan dengan cara mengonversi pangan yang dikonsumsi dari bentuk Ukuran Rumah Tangga (URT) menjadi gram. Setelah itu berat pangan yang berbentuk gram akan dikonversikan ke dalam bentuk satuan energi yaitu kilokalori. Berikut merupakan rata-rata konsumsi energi rumah tangga di Desa Kalirejo, Kecamatan Kokap, Kabupaten Kulon Progo.

Tabel 6. Konsumsi Energi Rumah Tangga di Desa Kalirejo

\begin{tabular}{|c|c|}
\hline Kelompok Pangan & $\begin{array}{c}\text { Konsumsi riil } \\
\text { (kkal/kap/hari) }\end{array}$ \\
\hline Padi-padian & $1.359,61$ \\
\hline Umbi-umbian & 34,96 \\
\hline Pangan Hewani & 147,30 \\
\hline Minyak dan Lemak & 115,08 \\
\hline Buah/ Biji berminyak & 56,06 \\
\hline Kacang-kacangan & 164,57 \\
\hline Gula & 24,34 \\
\hline Sayur dan Buah & 163,54 \\
\hline Lain-lain & 233,81 \\
\hline Total & $2.208,48$ \\
\hline
\end{tabular}

Sumber : Analisis Data Primer, 2020

Berdasarkan tabel 6, dapat diketahui bahwa total konsumsi energi rumah tangga di Desa Kalirejo sebesar 2.208,48 kkal/kap/hari. Nilai konsumsi energi tersebut sudah lebih dari rekomendasi bila dibandingkan dengan Angka Kecukupan Energi anjuran nasional menurut Widyakarya Pangan dan Gizi (WNPG) ke XI tahun 2018 sebesar $2.100 \mathrm{kkal} / \mathrm{kap} / \mathrm{hari}$. Namun untuk persebaran konsumsi pangan sebagian besar masih terdapat dalam kelompok padi-padian saja. Berikut sebaran konsumsi energi rumah tangga di Desa Kalirejo. 
Jurnal Dinamika Sosisal Ekonomi, 21 (2) : 205-218

Tabel 7. Sebaran Konsumsi Energi Rumah Tangga di Kalirejo

\begin{tabular}{|c|c|c|c|}
\hline $\begin{array}{l}\text { Konsumsi } \\
\text { Energi }\end{array}$ & $\begin{array}{c}\text { Rata-rata Konsumsi } \\
\text { Energi (kkal/kap/hari) }\end{array}$ & $\begin{array}{c}\text { Jumlah Rumah } \\
\text { Tangga }\end{array}$ & Persentase $(\%)$ \\
\hline$<2.100$ & $1.635,99$ & 16 & 37,21 \\
\hline$>2.100$ & $2.547,74$ & 27 & 62,79 \\
\hline Total & $4.183,73$ & 43 & 100 \\
\hline
\end{tabular}

Sumber : Analisis Data Primer, 2020

Hasil sebaran konsumsi energi rumah tangga pada tabel 7 menunjukkan bahwa meskipun rata-rata konsumsi energi di Desa Kalirejo sudah memenuhi anjuran nasional menurut Widyakarya Pangan dan Gizi (WNPG) ke XI tahun 2018. Namun pada sebarannya masih terdapat rumah tangga yang belum memenuhi rekomendasi, yaitu sebesar 16 rumah tangga. Selain melihat konsumsi energi rumah tangga, penelitian ini juga menguji tingkat kecukupan energi rumah tangga menggunakan uji one sample t-test. Hipotesis yang digunakan dalam penelitian ini adalah kecukupan energi memiliki kategori cukup. Hasilnya sebagai berikut:

Tabel 8. Hasil Analisis One Sample t-test Tingkat Kecukupan Energi Rumah Tangga di Desa Kalirejo

\begin{tabular}{lcccc}
\hline \multicolumn{1}{c}{ Variabel } & N & Mean & t-hitung & P-value \\
\hline Tingkat Kecukupan Energi & 43 & 105,1658 & 6,317 &, 00 \\
\hline Test Value : 80 & & & & \\
\hline
\end{tabular}

Sumber : Analisis Data Primer, 2020

Tabel 8 menunjukkan bahwa hasil uji one sample t-test tingkat kecukupan energi rumah tangga di Desa Kalirejo, Kecamatan Kokap, Kabupaten Kulon Progo memiliki rata-rata 105,1658 \%. Apabila dibandingkan dengan klasifikasi Tingkat Kecukupan Energi dalam klasifikasi silang menurut Jonsson dan Toole (1991) dalam Dirhamsyah et al (2016). Nilai rata-rata Tingkat Kecukupan Energi sudah lebih dari $80 \%$ yang termasuk ke dalam kategori cukup.

\section{Tingkat Ketahanan Pangan Rumah Tangga}

Analisis tingkat ketahanan pangan rumah tangga dilakukan setelah mendapatkan nilai pangsa pengeluaran pangan (PPP) dan tingkat kecukupan energi (TKE) yang merupakan komponen untuk mengetahui tingkat ketahanan 
pangan rumah tangga. Kriteria ketahanan pangan diklasifikasikan berdasarkan pendapat Jonsson dan Toole (1991) dalam Dirhamsyah et al (2016), berikut ini merupakan sebaran tingkat ketahanan pangan rumah tangga di Desa Kalirejo.

Tabel 9. Sebaran Tingkat Ketahanan Pangan Rumah Tangga di Desa Kalirejo

\begin{tabular}{|c|c|c|}
\hline \multirow[b]{2}{*}{$\begin{array}{c}\text { Indikator Klasifikasi Silang } \\
\text { Pengukuran Derajat } \\
\text { Ketahanan Pangan }\end{array}$} & \multicolumn{2}{|c|}{ Pangsa Pengeluaran Pangan } \\
\hline & $\begin{array}{c}\text { Rendah } \\
\text { ( }<60 \% \text { pengeluaran } \\
\text { total) }\end{array}$ & $\begin{array}{c}\text { Tinggi } \\
\text { ( } \geq 60 \% \text { pengeluaran } \\
\text { total) }\end{array}$ \\
\hline $\begin{array}{c}\text { Konsumsi Energi per Unit } \\
\text { Ekuivalen Dewasa } \\
\text { Cukup } \\
\text { (>80\% kecukupan energi) }\end{array}$ & $\begin{array}{l}\quad \text { Tahan Pangan } \\
\mathrm{TKE}=113,14 \% \\
\mathrm{PPP}=37,73 \% \\
\text { Jumlah }=7 \mathrm{KK} \\
\text { Persentase }=16,28 \% \\
\end{array}$ & $\begin{array}{l}\quad \text { Rentan Pangan } \\
\text { TKE }=112,91 \% \\
\text { PPP }=73,26 \% \\
\text { Jumlah }=29 \mathrm{KK} \\
\text { Persentase }=67,44 \% \\
\end{array}$ \\
\hline $\begin{array}{c}\text { Kurang } \\
(\leq 80 \% \text { kecukupan energi) }\end{array}$ & $\begin{array}{l}\text { Kurang Pangan } \\
\text { TKE }=0 \\
\mathrm{PPP}=0 \\
\text { Jumlah }=0 \\
\text { Persentase }=0\end{array}$ & $\begin{array}{l}\text { Rawan Pangan } \\
\mathrm{TKE}=65,13 \% \\
\mathrm{PPP}=71,72 \% \\
\text { Jumlah }=7 \mathrm{KK} \\
\text { Persentase }=16,28 \%\end{array}$ \\
\hline
\end{tabular}

Sumber : Analisis Data Primer, 2020

Berdasarkan tabel 9 dapat diketahui bahwa klasifikasi silang antara indikator ketahanan pangan, yaitu tingkat kecukupan energi dan pangsa pengeluaran pangan untuk mendapatkan tingkat ketahanan pangan. Sebagian besar rumah tangga di Desa Kalirejo termasuk ke dalam kategori rentan pangan, sejumlah 29 rumah tangga atau sejumlah 67,44\%. Kondisi rentan pangan ditunjukkan oleh proporsi pangsa pengeluaran pangan $\geq 60 \%$ dan tingkat kecukupan energinya $>80 \%$ kecukupan energi.

\section{Faktor-faktor yang Berpengaruh terhadap Konsumsi Pangan}

Hasil analisis regresi linear berganda disajikan pada tabel 10. Hipotesis yang diajukan adalah diduga pendidikan ibu rumah tangga, jumlah anggota rumah tangga dan pendapatan berpengaruh terhadap konsumsi pangan. 
Jurnal Dinamika Sosisal Ekonomi, 21 (2) : 205-218

Tabel 10 Hasil Analisis Regresi Linear Berganda Pengaruh Faktor-faktor terhadap Konsumsi Pangan Rumah Tangga di Desa Kalirejo

\begin{tabular}{lccc}
\hline \multicolumn{1}{c}{ Variabel } & $\begin{array}{c}\text { Koefisien } \\
\text { Regresi }\end{array}$ & t-hitung & Sig \\
\hline Konstanta & $1.139,010$ & 5,895 & 0,000 \\
Lama Pendidikan Ibu Rumah Tangga & 47,496 & 2,844 & 0,007 \\
Jumlah Anggota Rumah Tangga & 158,232 & 2,994 & 0,005 \\
Pendapatan & 9,674 & 2,255 & 0,030 \\
\hline Adj $\mathrm{R}^{2}=0,506$ & F hitung $=15,349$ Sig $=0,000$ & \\
\hline
\end{tabular}

Sumber $=$ Analisis Data Primer, 2020

Hasil penelitian pada tabel 10 menunjukkan hasil uji F yaitu faktor-faktor tersebut berpengaruh secara bersama-sama terhadap konsumsi pangan dengan nilai siginifikansi sebesar 0,00 . Untuk uji individu atau uji t, menunjukkan bahwa lama pendidikan ibu rumah tangga berpengaruh positif terhadap konsumsi pangan dengan nilai signifikansi 0,007 . Hal tersebut sesuai dengan hasil penelitian Ambarsari (2017) yaitu lama tingkat pendidikan formal ibu rumah tangga akan semakin mempertimbangan gizi yang dikandung dalam pangannya, selain itu juga jenis pangan yang dikonsumsi akan semakin beranekaragam dibanding ibu rumah tangga yang pendidikannya lebih singkat.

Jumlah anggota rumah tangga juga berpengaruh positif terhadap konsumsi pangan dengan nilai signifikansi sebesar 0,005 . Hasil pengujian tersebut sejalan dengan penelitian Adiana dan Karmini (2012) yang menyatakan bahwa apabila semakin banyak jumlah anggota rumah tangga maka semakin banyak pula jumlah kebutuhan keluarga yang harus dipenuhi. Jumlah anggota keluarga yang semakin banyak maka konsumsi pangan dengan pola akan bervariasi karena setiap masing masing anggota rumah tangga belum tentu memiliki selera rumah tangga.

Pendapatan rumah tangga juga berpengaruh terhadap konsumsi pangan dengan hasil signifikasin 0,030. Hasil penelitian tersebut menunjukkan pengaruh positif pendapatan terhadap konsumsi pangan. Hal tersebut bertentangan dengan Engel yang menyatakan bahwa kenaikan pendapatan cenderung kurang diikuti dengan kenaikan konsumsi untuk pangan. Kondisi pendapatan berpengaruh positif tersebut akan terus terjadi karena rata-rata pendapatan rumah tangga sebesar Rp 1.436.860 yang masih rendah dan tergolong dibawah garis kemiskinan. Garis 
kemiskinan tersebut berdasarkan nilai Upah Minimum Regional (UMR) Kabupaten Kulon Progo tahun 2020 yaitu sebesar Rp 1.750.500. Kenaikan akan terjadi sampai pendapatan tersebut sama dengan atau lebih dari Upah Minimum Regional (UMR).

Untuk uji ketepatan model, diketahui bahwa nilai koefisien determinasi sebesar 0,506. Hal tersebut menunjukkan bahwa 50,6\% variasi pada konsumsi pangan (variabel terikat) dapat dijelaskan oleh lama pendidikan ibu rumah tangga, jumlah anggota rumah tangga dan pendidikan (variabel bebas). Sedangkan 49,4\% sisanya dijelaskan oleh variabel lain yang tidak dimasukkan ke dalam model regresi. Berikut merupakan persamaan regresi liniear berganda:

$$
y=1.139,010+47,496 x_{1}+158,232 x_{2}+9,674 x_{3}+e
$$

\section{Keterangan :}

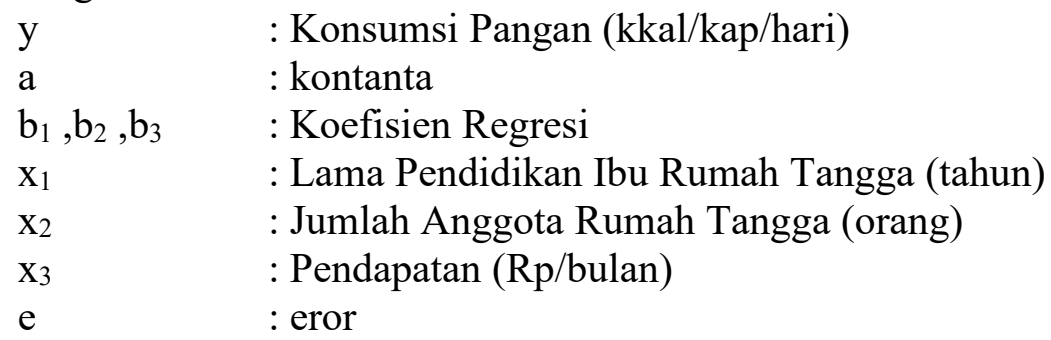

\section{KESIMPULAN DAN SARAN}

\section{Kesimpulan}

Tingkat ketahanan pangan rumah tangga di Desa Kalirejo, Kecamatan Kokap, Kabupaten Kulon Progo berada dalam kategori rentan pangan. Selain itu, terdapat beberapa faktor yang berpengaruh terhadap konsumsi pangan di Desa Kalirejo, Kecamatan Kokap, Kabupaten Kulon Progo yaitu lama pendidikan ibu rumah tangga, jumlah anggota rumah tangga dan pendapatan.

\section{Saran}

Untuk meningkatkan tingkat ketahanan pangan dapat dilakukan dengan pemerataan informasi mengenai Kawasan Rumah Pangan Lestari (KRPL) melalui penyuluhan dan pelatihan secara berkala, sehingga seluruh masyarakat dapat menerapkan program tersebut dan memiliki sumber pangan sendiri serta tambahan pendapatan. 
Jurnal Dinamika Sosisal Ekonomi, 21 (2) : 205-218

\section{DAFTAR PUSTAKA}

Adiana, Pande Putu Erwin dan Karmini, Ni Luh. (2012). Pengaruh Pendapatan, Jumlah Anggota Keluarga dan Pendidikan Terhadap Pola Konsumsi Rumah Tangga Miskin di Kecamatan Gianyar. E-Jurnal Ekonomi Pembangunan Universitas Udayana (EEP), 1(1) :39-48.

Ambarsari, Erlin Ratna. (2017). Analisis Ketersediaan Pangan Pokok dan Konsumsi Energi Rumah Tangga Petani di Desa Tuksono Kecamatan Sentolo Kabupaten Kulon Progo. Skripsi. Program Studi Agribisnis, Fakultas Pertanian, Universitas Pembangunan Nasional "Veteran" Yogyakarta.

Arida, Agustina. (2015). Analisis Ketahanan Pangan Rumah Tangga Berdasarkan Proporsi Pengeluaran Pangan dan Konsumsi Energi Jurnal Agrisep, 16 (1) :20-34.

BPS. (2018). Kabupaten Kulonprogo dalam Angka. Jakarta : Badan Pusat Statistik.

Dinas Pertanian dan Ketahanan Pangan. (2018). Laporan Sistem Kewaspadaan Pangan dan Gizi. Diakses pada tangga 3 Oktober 2020 dari www.pertanian.kulonprogokab.go.id.

Delly, Defline Putri. (2018). Analisis Tingkat Ketahanan Pangan Rumah Tangga Nelayan di Desa Sukajaya Lempasing Kecamatan Teluk Pandan Kabupaten Pesawaran. E-Jurnal Ilmu Agribisnis Universitas Lampung, 7 (2) : $141-153$.

Dirhamsyah, Tedy, Jangkung Handoyo Mulyo, Dwidjono Hadi Darwanto, Slamet Hartono. (2016). Ketahanan Pangan Kemandirian Pangan dan Kesejahteraan Masyarakat Daerah Rawan Pangan di Jawa. Yogyakarta : Plantaxia.

Mayasari, Dewi, Dias Satria, Iswan Noor. (2018). Analisis Pola Konsumsi Pangan Berdasarkan Status IPM di Jawa Timur. E-Jurnal Ekonomi Pembangunan Indonesia , 18 (2) : 191-213.

Nicholson, Walter. (1985). Teori Ekonomi Mikro. Jakarta : PT Raja Grafindo Persada.

Sitompul, Kristina Hariyani. (2016). Analisis Pola Konsumsi Pangan Rumah Tangga Miskin. E-Jurnal Sosial Ekonomi Pertanian dan Agribisnis ,5 (9) : 1-10.

Sugiyono. (2017). Metode Penelitian Kuantitatif, Kualitatif dan R\&D. Bandung : Penerbit Alfabeta.

Suryana, Achmad. (2014). Menuju Ketahanan Pangan Indonesia Berkelanjutan 2025: Tantangan dan Penangannya. Forum Penelitian Agro Ekonomi ,32 (2) : 123-135. 